\title{
Extending the Concept of Predicting Fish Acute Toxicity In Vitro to the Intestinal Cell Line RTgutGC
}

\author{
Hannah Schug1,2, Jenny Maner 1, Maren Hülskamp 1,3, Frédéric Begnaud 4, Christian Debonneville4, \\ Fabienne Berthaud4, Sylvia Gimeno ${ }^{5}$ and Kristin Schirmer ${ }^{1,2,6}$ \\ ${ }^{1}$ Eawag, Swiss Federal Institute of Aquatic Science and Technology, Dübendorf, Switzerland; ${ }^{2}$ EPF Lausanne, School of Architecture, Civil and \\ Environmental Engineering, Lausanne, Switzerland; ${ }^{3}$ University of Duisburg-Essen, Essen, Germany; ${ }^{4}$ Firmenich International SA, Geneva, Switzerland; \\ ${ }^{5}$ Firmenich Belgium SA, Louvain-La-Neuve, Belgium; ${ }^{6}$ ETH Zürich, Swiss Federal Institute of Technology, Institute of Biogeochemistry and Pollutant \\ Dynamics, Zürich, Switzerland
}

\begin{abstract}
Testing chemicals for fish acute toxicity is a legal requirement in many countries as part of environmental risk assessment. To reduce the number of fish used, substantial efforts have been focused on alternative approaches. Prominently, the cell viability assay with the rainbow trout (Oncorhynchus mykiss) gill cell line, RTgill-W1, has proven to be highly predictive and robust. Like the gills, the intestine is considered a major site of chemical uptake and biotransformation, but, in contrast to the gills, it is expected to be exposed to more hydrophobic chemicals, which enter the fish via food. In the present study, we therefore aimed to extend the cell bioassay to the rainbow trout epithelial cell line from intestine, RTgutGC. Using 16 hydrophobic and volatile chemicals from the fragrance palette, we show that also the RTgutGC cell line can be used to predict fish acute toxicity of chemicals and yields intra-laboratory variability in line with other bioassays. By comparing the RTgutGC toxicity to a study employing the RTgill-W 1 assay on the same group of chemicals, a fragrance-specific relationship was established that reflects an almost perfect $1: 1$ relationship between in vitro and in vivo toxicity results. Thus, both cell lines can be used to predict fish acute toxicity, either by extrapolating based on the in vivo-in vitro relationship or by taking the in vitro results at face value. We moreover demonstrate the derivation of non-toxic concentrations for downstream applications that rely on a healthy cell state, such as the assessment of biotransformation or chemical transfer.
\end{abstract}

\section{Introduction}

Fish acute toxicity is an important criterion in chemical screening for product development and environmental hazard and risk assessment, whereby the fish acute toxicity test is conducted according to OECD TG 203 (OECD, 2019). Thus, conventionally, an in vivo test is conducted where juvenile or adult fish are exposed to the chemical for $96 \mathrm{~h}$ to determine the concentration that causes $50 \%$ fish lethality $\left(\mathrm{LC}_{50}\right)$. This test is required for registration of any chemical produced or imported in amounts $\geq 10$ tons per year in the European Union under the Registration, Evaluation, Authorisation and Restriction of Chemicals
(REACH) (EC, 2006) legislation and requires the sacrifice of at least 42 animals.

In order to reduce animal use, a concept to derive fish acute toxicity predictions using a fish cell line-based approach has been established over the past decade (Schirmer, 2006, 2008; Tanneberger et al., 2010, 2013). Because the gill is the primary target of waterborne toxicants and thus a main site of interaction for shortterm chemical exposure, the RTgill-W1 cell line from rainbow trout (Oncorhynchus mykiss) (Bols et al., 1994) was selected for this approach. The RTgill-W1 cells remain viable upon exposure to simple buffers, such as the serum-free exposure medium L-15/ex. L-15/ex is ideal for chemical exposure because the ab-
Received May 3, 2019; Accepted July 1, 2019; Epub July 11, 2019; ( ) The Authors, 2019.

ALTEX 37(1), 037-046. doi:10.14573/altex.1905032

Correspondence: Prof. Kristin Schirmer

Environmental Toxicology, Eawag

Swiss Federal Institute of Aquatic Science and Technology

Überlandstrasse 133, 8600 Dübendorf, Switzerland

(kristin.schirmer@eawag.ch)

Frédéric Begnaud, PhD

Corporate R\&D Division / Analytical Innovation, Firmenich SA

Route des Jeunes 1, 1211 Geneva, Switzerland

(frederic.begnaud@firmenich.com)
This is an Open Access article distributed under the terms of the Creative Commons Attribution 4.0 International license (http://creativecommons.org/licenses/by/4.0/) which permits unrestricted use, distribution and reproduction in any medium, provided the original work is appropriately cited. 
sence of protective components present in complex culture media, especially fetal bovine serum (FBS), avoids potential interference with the chemical, while the composition is a good representation of the in vivo exposure situation (Schirmer et al., 1997; Tanneberger et al., 2010, 2013).

Extensive confirmation of the predictive ability of the RTgill-W1 cell line assay for fish acute toxicity was first presented by Tanneberger et al. (2013), who explored 35 industrial chemicals and pesticides with a wide range of physicochemical properties (octanol-water partition coefficient: $\log \mathrm{K}_{\mathrm{ow}}-4.2$ to 7.4 and Henry's law constant: $\log$ HLC -13 to -0.7 ), modes of action (i.e., narcotic, reactive, uncoupler and neurotoxic), and acute toxicity to fish $\left(\mathrm{LC}_{50}\right.$ from 0.005 to $\left.49741 \mathrm{mg} / \mathrm{L}\right)$. They found a very good agreement between the in vitro effective concentrations causing a $50 \%$ decline in cell viability $\left(\mathrm{EC}_{50}\right)$ and the in vivo lethal concentrations $\left(\mathrm{LC}_{50}\right)$. Indeed, for $73 \%$ of the test chemicals, the differences between $\mathrm{EC}_{50}$ and $\mathrm{LC}_{50}$ values were less than five-fold. The few exceptions for which the difference was more than ten-fold from the line of unity were well explainable by prior knowledge from mammalian data and the mode of action of the chemicals. An international round-robin study using a subset of the Tanneberger et al. (2013) test chemicals confirmed the robustness of the assay and its intra- and inter-laboratory variability to be within the range of those previously reported for comparable small-scale bioassays (Fischer et al., 2019). In addition, Natsch et al. (2018) tested 38 fragrance chemicals with a considerable range of physicochemical properties $\left(\log \mathrm{K}_{\mathrm{ow}} 0\right.$ to 6.7 and $\operatorname{logHLC}-6.7$ to -2.9$)$ with the RTgill-W1 cell line assay. They also found a very good agreement between $\mathrm{EC}_{50}$ cell line and $\mathrm{LC}_{50}$ fish toxicity, confirming the predictive capacity of the cell line-based assay. The RTgill-W1 cell line-based assay has recently been adopted as ISO guideline 21115 (ISO, 2019).

Like the gills, the intestine represents a major site of chemical interaction and toxicity. A representative cell line, the rainbow trout intestinal epithelial cell line, RTgutGC (Kawano et al., 2011), has thus far been applied to understand and predict chemical impact on fish beyond acute toxicity. One example is the prediction of the bioaccumulation potential of chemicals in fish. In this context, Stadnicka-Michalak et al. (2018a) demonstrated the capability of the RTgutGC cell line, along with the RTgill-W1 cell line and the rainbow trout liver cell line, RTL-W1 (Lee et al., 1993), to biotransform benzo(a)pyrene and to provide in vitro clearance rates that can be used to derive fish bioconcentration factors (BCF). Here, justification of the use of the RTgutGC cell line lies in the fact that, like the gill, the intestine is considered a major site of chemical uptake and extra-hepatic biotransformation by fish (Armitage et al., 2016). In contrast to the gill, the intestine is expected to be exposed to rather hydrophobic chemicals, which sorb to organic matter including fish food and thus enter the organism via the intestine. Efforts are thus underway to use the RTgutGC cell line as an epithelial intestinal barrier model to shed light on chemical-intestine interactions in fish (Schug et al., 2018, 2019; Minghetti et al., 2017; Geppert et al., 2016; Langan et al., 2017; Wang et al., 2019).
Given the potential of using the growing set of cell lines of different tissue origin to build a modular in vitro surrogate of a fish, we here hypothesized that, on top of RTgill-W1, the RTgutGC cell line can be used to predict fish acute toxicity of chemicals. Like the RTgill-W1 cell line, RTgutGC cells are stable over the course of several days in the simple L-15/ex exposure medium (Minghetti et al., 2017; Minghetti and Schirmer, 2016), which facilitates defined chemical exposure as explained above. Establishing the RTgutGC cell line for viability measurements is also of importance for many downstream applications, such as biotransformation assessments (Stadnicka-Michalak et al., 2018a) or the study of chemical interaction and transfer across intestinal epithelial cells (Schug et al., 2018, 2019; Minghetti et al., 2017; Wang et al., 2019). These studies are generally conducted using non-toxic chemical exposure concentrations (NtCs), which can be safely derived only from a full concentration-response analysis of cell viability (Stadnicka-Michalak et al., 2018b).

Fragrance ingredients ("fragrances") are a suitable group of chemicals for testing acute toxicity via cell-based assays as they are, for example, expected to predominantly act via baseline toxicity (Natsch et al., 2018). At the same time, fragrances tend to be small, rather hydrophobic $\left(\log K_{\mathrm{ow}}>3\right)$ molecules and thus would be expected to enter the fish via food through the intestine. Fragrances are also rather volatile, which we define as having a $\operatorname{logHLC}>-5.6$ (Tanneberger et al., 2013), and, consequently, challenging to test. Thus, in the present study, we determined $\mathrm{EC}_{50}$ values for a set of fragrances using the RTgutGC cell line based on three measures of cell viability: metabolic activity, cell and lysosomal membrane integrity. Fragrances were selected to span a wide range of physicochemical properties $\left(\log \mathrm{K}_{\mathrm{ow}} 1.8\right.$ to 6.3 and $\log \mathrm{HLC}-6.8$ to -2.3 ) and $\mathrm{LC}_{50}$ values available from fish ( $\mathrm{LC}_{50}$ from 0.06 to $14.4 \mathrm{mg} / \mathrm{L}$ ). We also provide NtCs (Stadnicka-Michalak et al., 2018b) for future applications with sub-lethal interactions of the fragrances with the fish intestinal cells and establish quantitative structure-activity relationships (QSARs) based on the $\log \mathrm{K}_{\mathrm{ow}}$ of the chemicals. Collectively, this research extends the concept of predicting the acute toxicity of chemicals to fish in vitro with the aim to reduce and replace one of the most severe and frequently carried out fish tests.

\section{Materials and methods}

\subsection{Test chemicals}

All test chemicals are fragrances from Firmenich SA. The chemicals were selected to span a range of physicochemical properties, i.e., octanol-water partition coefficient $\left(\log \mathrm{K}_{\mathrm{ow}}\right)$ and volatility (Henry - law constant $=\operatorname{logHLC}$ ), as well as fish acute in vivo toxicity (in vivo). In vivo fish acute toxicity data were available for 10 of the 16 chemicals, having been obtained from four different species. In addition, the $96 \mathrm{~h} \mathrm{LC}_{50}$ values for all chemicals were predicted using QSARs (EPISuite 4.11 ECOSAR). The identity of chemicals, their physicochemical properties as well as measured and predicted $\mathrm{LC}_{50}$ values along with the tested fish species are presented in Table 1. 
Tab. 1: Physicochemical properties and in vivo $\mathrm{LC}_{50}$ data of test chemicals

Test chemicals are sorted according to their log $\mathrm{K}_{\mathrm{ow}}$ from low to high. All presented physicochemical properties are based on measured data if not stated otherwise. Measured fish acute toxicity data are company internal data provided by Firmenich SA. Chemicals with a $\log \mathrm{K}_{\mathrm{ow}}>3$ were considered hydrophobic and chemicals with a logHLC $>-5.6$ volatile.

\begin{tabular}{|c|c|c|c|c|c|c|c|c|}
\hline Chemical & Abbr. & $\begin{array}{l}\text { MW } \\
(\mathrm{Da})\end{array}$ & $\log K_{\text {ow }}$ & $\begin{array}{l}\text { WS } \\
\text { (mg/L) }\end{array}$ & $\log \mathrm{HLC}$ & $\begin{array}{l}\text { Pred. } \text { LC }_{50}(\mathrm{mg} / \mathrm{L}) \\
\text { (ECOSAR } \\
\text { chemical class) }\end{array}$ & $\begin{array}{l}\text { Meas. } \\
\text { LC } C_{50} \\
(\mathrm{mg} / \mathrm{L})\end{array}$ & Tested species \\
\hline Eugenol F & EugF & 164.2 & 1.83 & 1154 & -6.1 & $\begin{array}{l}38.3 \text { (phenol) } \\
191 \text { (neutral) }\end{array}$ & 13 & Zebra fish (D. rerio) \\
\hline Methyl-antranilate & MetA & 151.2 & 2.17 & 2790 & -6.1 & $\begin{array}{l}16 \text { (ester) } \\
87 \text { (neutral) } \\
46 \text { (aniline) }\end{array}$ & 9.12 & $\begin{array}{l}\text { Bluegill sunfish } \\
\text { (L. macrochirus) }\end{array}$ \\
\hline Lilyflore $^{\circledR}$ & Lil & 176.3 & 2.94 & 609 & -6.8 & 25.49 (neutral) & 14.4 & $\begin{array}{l}\text { Rainbow trout } \\
\text { (O. mykiss) }\end{array}$ \\
\hline Damascone beta & $\mathrm{DaB}$ & 192.3 & 3.68 & 194 & -3.5 & $\begin{array}{l}10.23 \text { (vinyl alyl) } \\
4.89 \text { (neutral) }\end{array}$ & 1.09 & Ricefish (O. latipes) \\
\hline Helvetol & $\mathrm{Hel}$ & 228.4 & 4.33 & $37.5 a$ & -5.9 & 1.5 (neutral) & n.d. & Pred. ECOSAR \\
\hline Pamplewood & $\mathrm{Pa}$ & 208.3 & 4.60 & 7.07 & -2.3 & 0.70 (neutral) & n.d. & Pred. ECOSAR \\
\hline Veloutone $^{\circledR}$ & Vel & 196.3 & 4.70 & 18.9 & -3.1 & 0.61 (neutral) & n.d. & Pred. ECOSAR \\
\hline Verdox $^{\circledR}$ & Ver & 198.3 & 4.75 & 10.0 & -2.7 & $\begin{array}{l}0.50 \text { (neutral) } \\
0.61 \text { (ester) }\end{array}$ & 5.6 & Zebrafish $(D$. rerio) \\
\hline Nirvanol $^{\circledR}$ & Nir & 222.4 & 4.99 & 13.0 & -3.7 & 0.38 (neutral) & 1.1 & Zebrafish (D. rerio) \\
\hline Cetalox $^{\circledR}$ & Cet & 236.4 & 5.09 & 1.9 & -4.6 & 0.33 (neutral) & $>0.51^{b}$ & Zebrafish $(D$. rerio) \\
\hline Cachalox $^{\circledR}$ & Cax & 236.4 & 5.09 & 1.9 & -3.2 & 0.33 (neutral) & $>0.51^{b}$ & Zebrafish (D. rerio) \\
\hline Exaltenone & Exa & 222.4 & 5.15 & 2.9 & -4.4 & 0.27 (neutral) & n.d. & Pred. ECOSAR \\
\hline Alpinolide & Alp & 282.4 & 5.20 & 1.94 & -6.2 & $\begin{array}{l}0.61 \text { (acrylate) } \\
0.28 \text { (neutral) }\end{array}$ & n.d. & Pred. ECOSAR \\
\hline Muscenone ${ }^{\circledR}$ delta & MuD & 236.4 & 5.52 & 0.1 & -4.2 & 0.13 (neutral) & 0.22 & $\begin{array}{l}\text { Rainbow trout } \\
\text { (O. mykiss) }\end{array}$ \\
\hline Tonalide $^{\circledR}$ & To & 258.4 & 5.70 & 1.2 & -4.8 & 0.10 (neutral) & 0.314 & $\begin{array}{l}\text { Bluegill sunfish } \\
\text { (L. macrochirus) }\end{array}$ \\
\hline Vulcanolide ${ }^{\circledR}$ & Vul & 258.4 & 6.25 & $0.03^{a}$ & -5.0 & $\begin{array}{l}0.10 \text { (aldehyde) } \\
0.03 \text { (neutral) }\end{array}$ & n.d. & Pred. ECOSAR \\
\hline
\end{tabular}

MW, molecular weight; WS, water solubility; n.d., not determined. ${ }^{a}$ predicted (EPISuite WSKOWIN) based on logK $\mathrm{K}_{\mathrm{ow}}$;

${ }^{\mathrm{b}}$ not used for in vitro - in vivo regression analysis due to ambiguity

\subsection{Routine RTgutGC cell culture}

The intestinal epithelial cell line from rainbow trout (Oncorhynchus mykiss), RTgutGC (Kawano et al., 2011), is routinely cultured with Leibovitz L-15 medium (Invitrogen, Basel, Switzerland) supplemented with $5 \%$ fetal bovine serum (FBS; PAA, Basel, Switzerland) and 1\% gentamycin (PAA, Basel, Switzerland) (= complete medium, L-15/FBS). Cells are cultured at $19 \pm 1^{\circ} \mathrm{C}$ in the absence of light in ambient atmosphere. They are sub-cultured every 7 to 10 days by washing the cells twice with Versene followed by trypsinization (Biowest, Nuaillé, France). The cells were tested monthly to establish that they were mycoplasma-free using the MycoAlert ${ }^{\circledR}$ Mycoplasma Detection Kit (Lonza, Basel, Switzerland). The RTgutGC cells were initiated by K. Schirmer in the laboratory of Prof. Niels Bols at the University of Waterloo in Canada and were confirmed to be of rainbow trout origin via DNA barcoding (Kawano et al., 2011). For the presented results, passage numbers 60 to 110 were used.

\subsection{Implementation of the RTgutGC cell viability assay} Exposure design

To assess the cytotoxicity of the test chemicals in RTgutGC cells, the previously developed standard operating procedure (SOP) for the RTgill-W1 assay (Tanneberger et al., 2013; Fischer et al., 2019) was followed. Chemical stock solutions were prepared in DMSO and further diluted in the exposure medium L-15/ex, which is a simplified version of the commercial Leibovitz L-15 
cell culture medium, containing only the salts plus galactose and pyruvate (Schirmer et al., 1997). Some steps of the SOP, such as cell seeding number and attachment time, were adapted to the RTgutGC cell line as follows: RTgutGC cells were seeded in $1 \mathrm{~mL}$ of L-15/FBS at a density of 120,000 cells/mL into a 24 -well plate and left to attach for $48 \mathrm{~h}$ prior to chemical exposure. To obtain a sufficient volume of exposure medium for chemical analysis for three time points, two 24-well plates were seeded for each biological replicate. In total, six fragrance concentrations and a chemical-free solvent control were tested in technical triplicates per plate. In addition, one solvent-free L-15/ex and two cell-free wells were used for background determination. For each chemical, a cell viability range-finding test was conducted as pre-test to find the optimal concentration range as described below. This pretest started with the maximal water solubility as highest exposure concentration and five subsequent 1:2 to 1:10 dilution steps. The final concentration used for each test chemical can be found in Table $\mathrm{S}^{1}{ }^{1}$. Each chemical was tested in three independent biological replicates with cells from different passage numbers.

\section{Preparation of stock solutions and dosing mixtures}

The chemical stock solutions were prepared by dissolving the chemical in DMSO and subsequent dilution in DMSO. For the exposure of cells, the DMSO stock solution was further diluted 200x in the exposure medium L-15/ex to yield a final DMSO concentration of $0.5 \%(\mathrm{v} / \mathrm{v})$ (Tanneberger et al., 2013). The respective dosing mixtures were mixed thoroughly for at least 30 min on a horizontal shaker at approx. $300 \mathrm{rpm}$ before cell exposure. Stock solutions in DMSO and dosing mixtures in L-15/ex of all tested fragrances were prepared freshly on the day of exposure.

\section{Cell exposure and chemical sampling}

Prior to exposure, the culture medium L-15/FBS was aspirated and cells were washed with $1 \mathrm{~mL} \mathrm{~L}-15 / \mathrm{ex}$ per well to remove any remaining FBS. In one of the plates, $2.3 \mathrm{~mL}$ of dosing mixture per well of the different concentrations was added and then $300 \mu \mathrm{L}$ from each well was sampled immediately to determine the initial exposure concentration at $t_{0 \mathrm{~h}}$ via LC-MSMS, GC-MS or GC-FID, depending on the chemical (Tab. S2, S3 ${ }^{1}$ ). This plate was later used to sample for concentration determination at the end of exposure $\left(\mathrm{t}_{24 \mathrm{~h}}\right)$ and to measure cell viability. In the other plate, $2 \mathrm{~mL}$ of dosing mixture per well was added and then sampled after 2-3 h of exposure ( $\left.\mathrm{t}_{2-3 \mathrm{~h}}\right)$. In addition, $300 \mu \mathrm{L}$ of each dosing mixture and stock solution were sampled separately. For quantification, all samples except the DMSO stock solutions were diluted 1:1 with $\mathrm{MeOH}$ containing either $1 \mathrm{mg} / \mathrm{L}$ of the fragrance $\mathrm{DaB}$ or To as internal standard for final quantification, vortexed and frozen at $-20^{\circ} \mathrm{C}$ until chemical analysis. The stock solution was diluted 200x with $\mathrm{MeOH}$ directly before chemical analysis and mixed with the same amount of internal standard. A more detailed procedure of the chemical quantification can be found in the supplementary file (Tab. S2, $\mathrm{S} 3^{1}$ ). In contrast to already published studies (Fischer et al., 2019; Natsch et al., 2018; Tanneberger et al., 2013), the test plates were covered with a sheet of aluminum foil instead of adhesive foil to reduce loss of chemicals that are both volatile and hydrophobic. For chemicals with both these physicochemical properties, the adhesive foil is thought to act as a chemical sink, increasing the loss of chemical from the solution (Schreiber et al., 2008). Test plates were incubated at $19 \pm 1{ }^{\circ} \mathrm{C}$ in the absence of light for $24 \mathrm{~h}$.

\section{Cell viability assays}

After $24 \mathrm{~h}$ exposure ( $\left.\mathrm{t}_{24 \mathrm{~h}}\right), 300 \mu \mathrm{L}$ from each well were first sampled for quantification of the exposure concentration at the end of the experiment as described above. Cell viability was assessed in the same plate using a combination of three fluorescent dyes to assess metabolic activity (Alamar Blue), cell membrane integrity (5-carboxyfluorescein diacetate acetoxy-methyl ester CFDA-AM) and lysosomal membrane integrity (Neutral Red), as previously described (Tanneberger et al., 2013; Natsch et al., 2018; Fischer et al., 2019). Briefly, exposure medium was removed and cells were carefully washed with $1 \mathrm{~mL}$ of phosphate buffered saline (PBS, with $\mathrm{Mg}^{2+}$ and $\mathrm{Ca}^{2+}$ ). $400 \mu \mathrm{L}$ of $5 \%(\mathrm{v} / \mathrm{v})$ Alamar Blue and $4 \mu \mathrm{M}$ CFDA-AM solution were added per well and incubated for $30 \mathrm{~min}$. The fluorescence was recorded at excitation and emission wavelengths of $\lambda_{\mathrm{ex}} / \lambda_{\mathrm{em}} 530 / 590 \mathrm{~nm}$ for Alamar Blue and $\lambda_{\text {ex }} / \lambda_{\text {em }} 493 / 541 \mathrm{~nm}$ for CFDA-AM using a multiwell plate reader (Tecan Infinite 2000, Männedorf, Switzerland). The Alamar Blue / CFDA-AM solution was replaced with Neutral Red solution and incubated for $60 \mathrm{~min}$. Thereafter, cells were fixed and extracted, and Neutral Red fluorescence was measured at excitation and emission wavelengths of $\lambda_{\mathrm{ex}} / \lambda_{\mathrm{em}} 530 / 645 \mathrm{~nm}$.

\subsection{Data treatment and statistical evaluation}

For cell viability recordings, the background fluorescence was subtracted from absolute fluorescence values and normalized to the chemical-free solvent control. Concentrations resulting in $50 \%$ reduction of cell viability $\left(\mathrm{EC}_{50}\right)$ were determined by non-linear fitting of a two-parameter log-logistic equation in $\mathrm{R}$ (version R-3.3.0) and R studio (version 0.99.902) using an inhouse R-script ${ }^{2}$. The $95 \%$ confidence intervals $(95 \% \mathrm{CI})$ for each biological replicate were determined by profile likelihood analysis (Raue et al., 2009). $\mathrm{EC}_{50}$ values were calculated either based on nominal concentrations or on the mean of the measured concentrations (Tanneberger et al., 2013). Having three time points to calculate the $\mathrm{EC}_{50}$ based on measured concentrations neither improved nor impaired the $\mathrm{EC}_{50}$ derivations compared to using two measured time points (data not shown). Also, using arithmetic or geometric means of the measured concentrations did not affect the final results. Thus, in the presented results, only nominal and $\mathrm{EC}_{50}$ values based on the geometric means of all three measured concentrations are shown and discussed.

Coefficients of variation (CoVs) as a measure of intra-laboratory variability for the $\mathrm{EC}_{50}$ values were calculated by dividing the standard deviation of the biological $\mathrm{EC}_{50}$ replicates per

\footnotetext{
1 doi:10.14573/altex.1905032s

2 https://github.com/UtoxEawag/RTgillRoundRobin
} 


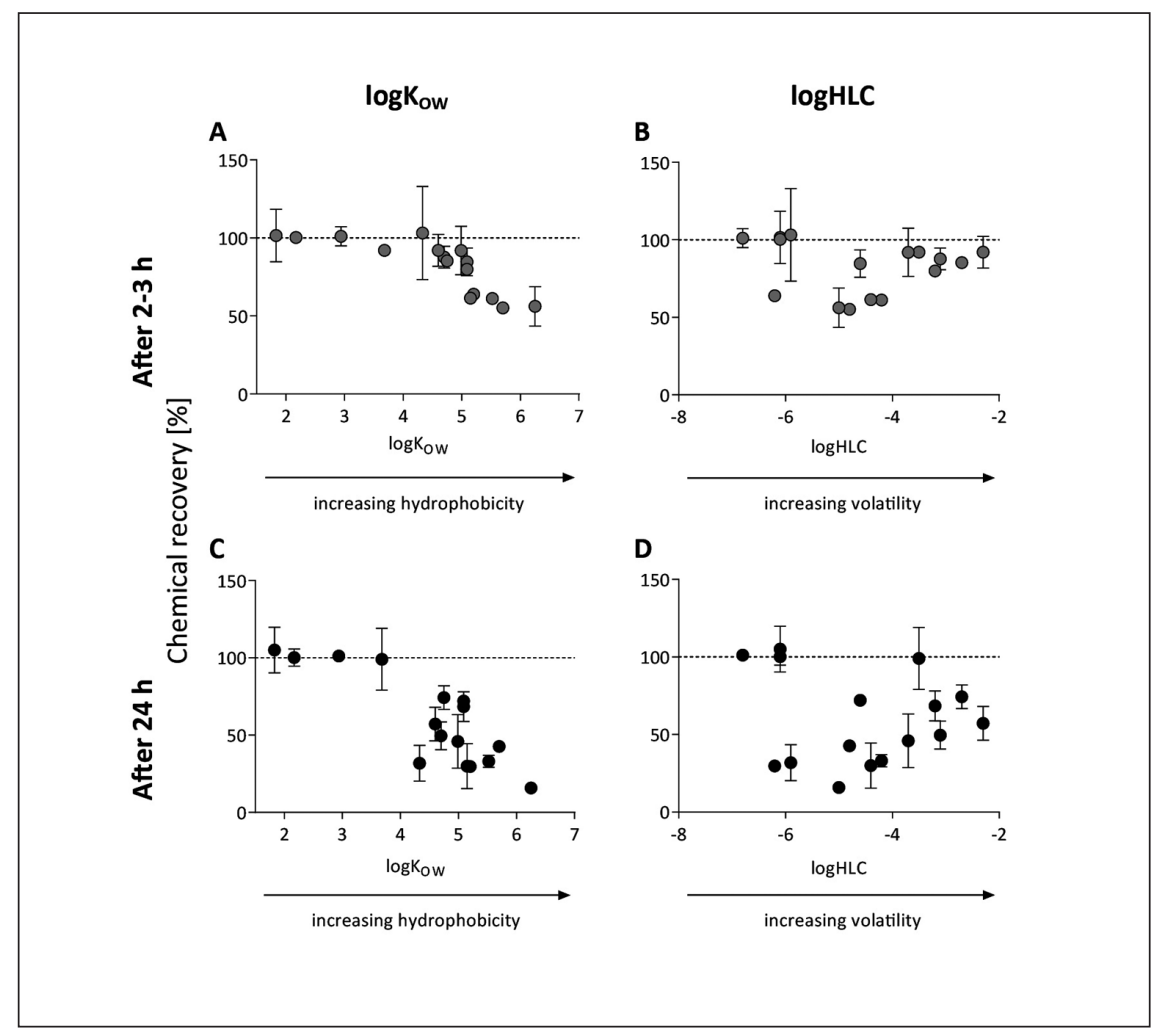

Fig. 1: Chemical recovery according to physicochemical properties

Measured chemical concentration of all dilution steps in the medium after 2-3 $\mathrm{h}$ and after $24 \mathrm{~h}$ of exposure was normalized to the respective concentration at the beginning of the experiment. Data are expressed in $\%$ and plotted as mean \pm SD of all dilution steps according to the log $\mathrm{K}_{\mathrm{ow}}$ (Panel A, C) and logHLC (Panel B, D). The dashed line indicates a full recovery. Numerical values are presented in Table S4 1 .

chemical by the mean of the $\mathrm{EC}_{50}$ (Fischer et al., 2019). The average of CoVs across all chemicals and the different cell viability dyes or methods of deriving the $\mathrm{EC}_{50}$ values, i.e., measured vs. nominal, were statistically analyzed by non-parametric KruskalWallis test.

$\mathrm{NtCs}$ for each cell viability endpoint were determined using the validated algorithm from Stadnicka-Michalak et al. (2018b) via an online application ${ }^{3}$.

Cell-based $\mathrm{EC}_{50}$ means $\pm \mathrm{SD}$ were plotted against fish acute $\mathrm{LC}_{50}$ data and analyzed by a Deming (type II) regression, assuming similar standard deviation for both data sets. QSARs were developed by plotting toxicity data $\left(\mathrm{EC}_{50}, \mathrm{LC}_{50}\right.$ or $\left.\mathrm{NtCs}\right)$ against $\log \mathrm{K}_{\mathrm{ow}}$ and by linear regression analysis. The presented QSARs were not validated according to OECD GD 69 (OECD, 2014).

\section{Results and discussion}

\subsection{Assessment of exposure concentrations}

In order to be able to express chemical toxicity based on actual exposure concentrations, we followed the recommendation by Tanneberger et al. (2013) and measured the exposure concentrations in the stock solutions, the dosing mixtures, at the beginning $\left(t_{0 h}\right)$ and at the end of the exposure $\left(t_{24 h}\right)$. In addition, to better understand chemical exposure concentrations between the begin- ning and the end of the exposure, the concentration after 2-3 $\mathrm{h}$ $\left(\mathrm{t}_{2-3 \mathrm{~h}}\right)$ was determined (Tab. $\mathrm{S} 4{ }^{1}$, Fig. $\left.\mathrm{S} 1, \mathrm{~S} 2^{1}\right)$. As in previous studies, the concentration in the wells at the beginning of the experiment matched the concentrations in the dosing mixtures, verifying that the dosing step was not a source of chemical loss (Tab. S4 ${ }^{1}$ ) (Natsch et al., 2018; Tanneberger et al., 2013; Fischer et al., 2019). However, once in the culture plate, a significant decrease of chemical concentration over time resulted for 12 out of 16 test chemicals, as indicated by the declining slopes of the measured versus nominal concentration relationships (Fig. S1 ${ }^{1}$ ). The chemical loss occurred non-linearly as shown by the $2-3 \mathrm{~h}$ measurement (Fig. S2L-P ${ }^{1}$ ). Strikingly, measured concentrations for Cax exceeded those of intended (nominal) concentrations, although the pattern of loss over time remained (Fig. S1K, S2K ${ }^{1}$ ).

Chemical loss increased with increasing hydrophobicity (Fig. 1A,C), whereas an apparent u-shape type relationship between chemical loss and volatility might be conceived (Fig. 1B,D). Over the course of the experiment, only chemicals with log$\mathrm{K}_{\mathrm{ow}} \leq 3.68$ remained stable in the exposure medium, whereas up to $84 \%$ of the chemical with the highest $\log \mathrm{K}_{\mathrm{ow}}$, Vul, were lost (Fig. 1C). Surprisingly, recovery for very volatile chemicals, i.e., with a logHLC close to -2, was higher than for less volatile chemicals with a $\log \mathrm{HLC}$ as low as -6 . As all volatile test chemicals in our data set were also hydrophobic, we assume that chemical binding to plastic components, driven by the $\log \mathrm{K}_{\mathrm{ow}}$,

3 https://utox.shinyapps.io/NtC_NtC/ 
Tab. 2: Fraction of hydrophobic and volatile chemicals and associated chemical loss

The fraction of chemicals with a $\log \mathrm{K}_{\mathrm{ow}}>3$ or $\log \mathrm{HLC}>-5.6$ and chemicals combining both properties was calculated for the present study and the studies presented by Natsch et al. (2018) and Tanneberger et al. (2013) based on the total number of chemicals tested. The percentage of chemical loss at the end of the exposure time for chemicals with both properties was calculated based on the measured concentration at the onset of the experiment.

\begin{tabular}{|c|c|c|c|c|c|}
\hline \multirow[t]{2}{*}{ Study } & \multicolumn{3}{|l|}{ Fraction (\%) } & \multirow[t]{2}{*}{ Total (n) } & \multirow{2}{*}{$\begin{array}{l}\text { Average loss of } \\
\text { volatile and } \\
\text { hydrophobic } \\
\text { chemicals (\%) }\end{array}$} \\
\hline & $\begin{array}{l}\text { Hydrophobic } \\
\text { chemicals } \\
(\text { logKow > } 3 \text { ) }\end{array}$ & $\begin{array}{l}\text { Volatile chemicals } \\
\text { (logHLC }>-5.6)\end{array}$ & $\begin{array}{l}\text { Hydrophobic and } \\
\text { volatile chemicals }\end{array}$ & & \\
\hline Present study & $81(n=13)$ & $69(n=11)$ & $69(n=11)$ & 16 & 47 \\
\hline Natsch et al., 2018 & $63(n=24)$ & $90(n=34)$ & $61(n=23)$ & 38 & 75 \\
\hline Tanneberger et al., 2013 & $43(n=15)$ & $37(n=13)$ & $17(n=6)$ & 35 & 86 \\
\hline
\end{tabular}

presents the dominant process of chemical loss. These results demonstrate the importance of taking both $\log \mathrm{K}_{\mathrm{ow}}$ and $\log \mathrm{HLC}$ into account.

\subsection{Evaluation of aluminum foil as cover method}

We covered the exposure plates with aluminum foil instead of adhesive foil in an attempt to reduce loss due to sorption into adhesive foil as demonstrated by Schreiber et al. (2008). Indeed, the average loss of hydrophobic and volatile chemicals $\left(\log \mathrm{K}_{\mathrm{ow}}\right.$ $>3$ and $\log$ HLC $>-5.6)$ in our study was $47 \%(n=11)$ and thus lower than the $86 \%(n=6)$ and $75 \%(n=23)$ found in the studies by Tanneberger et al. (2013) and Natsch et al. (2018) (Tab. 2). These criteria were met by $69 \%$ of the chemicals in our study, $61 \%$ in the study of Natsch et al. (2018), and $17 \%$ in the study of Tanneberger et al. (2013). However, the use of aluminum foil as a cover appears to have a drawback as well: Small amounts of the two chemicals with rather high $\operatorname{logHLC}(\mathrm{Pa}: \operatorname{logHLC}=-2.3$ and Vel: $\operatorname{logHLC}=-3.1)$ were found in the solvent control, and slightly higher than expected chemical masses were recovered for the two lowest exposure concentrations (Fig. S1F, G ${ }^{1}$ ). Thus, a potential future development could be the use of aluminum foil with a sealing mechanism for each well.

\subsection{Analysis of cell viability}

For 15 out of 16 chemicals, a reduction in cell viability was detected using all three fluorescent indicator dyes (Fig. S3 ${ }^{1}$ ). Only a slight decrease in lysosomal membrane integrity and no impact on metabolic activity or cell membrane integrity was found for Vul (Fig. S3AT-AV ${ }^{1}$ ). We suspect the high loss caused by the high $\log \mathrm{K}_{\mathrm{ow}}$ and $\log \mathrm{HLC}$ contributed to this lack of observable effect. For all other chemicals, $\mathrm{EC}_{50}$ values were determined and found to range from 0.4 to $310.9 \mathrm{mg} / \mathrm{L}$ (Fig. S4 and Tab. S5 ${ }^{1}$ ). Here, calculations were based on nominal and on geometric mean values of the three measured concentrations over time (Tab. S5 ${ }^{1}$ ).

As expected, for low $\log \mathrm{K}_{\mathrm{ow}}$ chemicals such as EugF, MetA, Lil and DaB, where no concentration loss occurred, the concentration-response curves and derived $\mathrm{EC}_{50}$ values were similar whether or not measured concentrations were taken into account
(Tab. $\left.5^{1}\right)$. For the remaining chemicals, the $\mathrm{EC}_{50}$ values based on measured concentrations were up to four times lower (MuD) than the nominal-derived $\mathrm{EC}_{50}$ concentration. An unusual case is that of Cax, for which the $\mathrm{EC}_{50}$ value for all cell viability measures based on measured concentration is about three times higher than that based on the nominal concentration, which is a consequence of the higher than expected measured concentrations. While we cannot provide an explanation for this unusual observation, it highlights again the value of analytically determining the actual exposure concentrations and expressing cell viability based on the measured concentrations.

When the $\mathrm{EC}_{50}$ values were compared across the three measures of cell viability, on average, metabolic activity was most sensitive, leading to $1.7( \pm 0.4)$-fold lower $\mathrm{EC}_{50}$ values than CFDA-AM and $1.4( \pm 0.4)$-fold lower $\mathrm{EC}_{50}$ values compared to Neutral Red (Fig. S4, Tab. S5 ${ }^{1}$ ). These findings are in very good agreement with the RTgill-W1 based assay (Fischer et al., 2019; Natsch et al., 2018; Tanneberger et al., 2013). Thus, in theory, the assay could be limited to the measure of metabolic activity alone. However, as reported previously (Schirmer et al., 1997; Fischer et al., 2019; Tanneberger et al., 2013), all three dyes give information about cell viability via the general mechanism of cell membrane disruption while at the same time providing specific information about their respective end point, i.e., cell metabolic activity (Alamar Blue), cell membrane integrity (CFDA-AM) and lysosomal membrane integrity (Neutral Red). The information from different cell viability dyes has already been used to identify specific modes of action of organic chemicals (Tanneberger et al., 2013; Schirmer et al., 2000) as well as silver nanoparticles (Yue et al., 2015). Conveniently, the dye mixture can be applied on the same set of cells. Thus, we support the recommendation by Fischer et al. (2019) to maintain all three cell viability measures to allow for further expansion of knowledge on different mechanisms of chemical action and on the value of the use of a panel of indicator dyes.

The $\mathrm{EC}_{50}$ values were further used to calculate the mean coefficient of variation $(\mathrm{CoV})$ as a measure of intra-laboratory variability as presented in the international validation study for the 


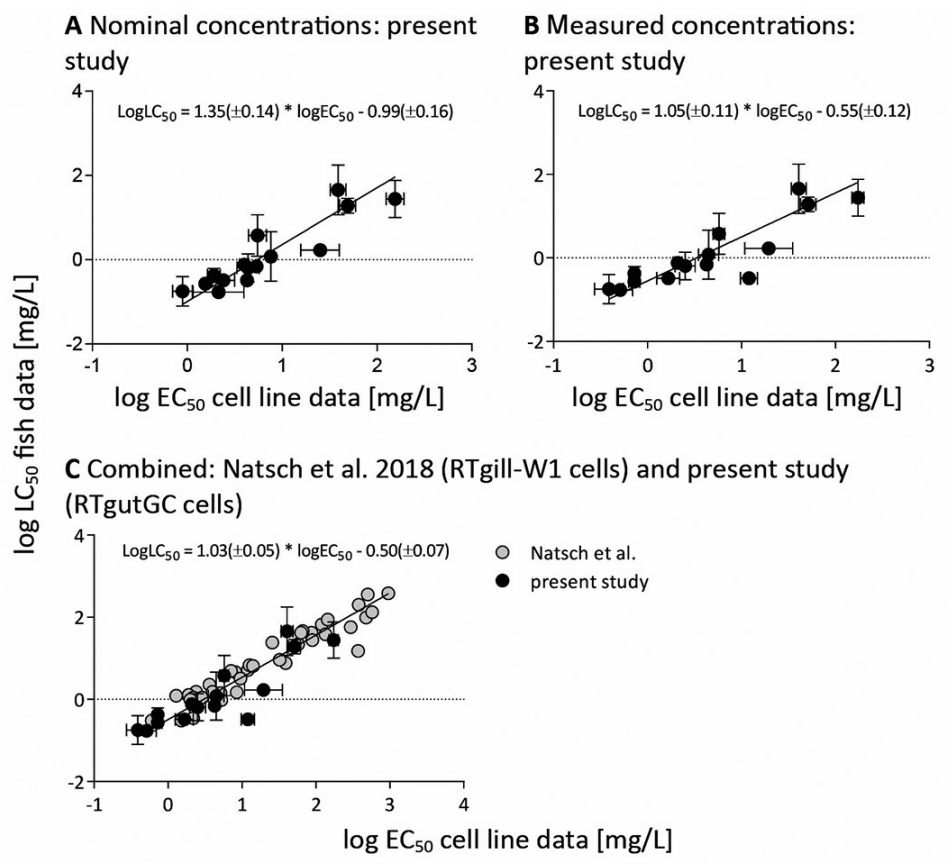

Fig. 2: In vitro to in vivo extrapolation model of acute fish toxicity prediction for fragrances using the measure of cell metabolic activity

A linear regression between $\mathrm{EC}_{50}$ values, based on cell metabolic activity (Tab. $\mathrm{S}^{1}{ }^{1}$ ) compared to fish acute toxicity $\mathrm{LC}_{50}$ values (Tab. 1) was established. RTgutGC $\mathrm{EC}_{50}$ values were calculated using the nominal concentration (Panel A) and geometric mean based on three measured concentrations ( $\mathrm{t}_{\mathrm{oh}}, \mathrm{t}_{2-3 \mathrm{~h}}$ and $\mathrm{t}_{24 \mathrm{~h}}$ ) (Panel B) and plotted against the mean of measured and predicted $\mathrm{LC}_{50}$ fish data. Cell line-based data are shown as mean $\pm S D$ of three biological replicates (RTgutGC, $n=3$ ). Panel $C$ shows RTgutGC EC $\mathrm{C}_{50}$ values based on measured concentrations (from Panel B) combined with data from Natsch et al. (2018) (grey filled circles, RTgill-W1, $n=1$ ). Solid line and equation represent a Deming (Model II) regression assuming equal uncertainties for $\mathrm{x}$ - and $\mathrm{y}$-values. Regressions based on cell and lysosomal membrane integrity are shown in Fig. $\mathrm{S}^{1}$.
RTgill-W1 assay (Fischer et al., 2019). The average CoV across all chemicals and dyes ranged from 15 to $29 \%$ (average $=21 \pm 3$ ) and did not statistically differ between different ways of deriving the $\mathrm{EC}_{50}$, i.e., nominal versus measured concentrations, or for the different cell viability dyes (Fig. S5 ${ }^{1}$ ). The CoVs are well comparable to the RTgill-W1 round-robin study results (Fischer et al., 2019), supporting the reliability of the method for another rainbow trout cell line.

In addition to the $\mathrm{EC}_{50}$ values, concentration-response curves were used to derive NtCs using the validated algorithm by Stadnicka-Michalak et al. (2018b). The NtCs of all chemicals span two orders of magnitude (Tab. S6 ${ }^{1}$ ), but, in contrast to the $\mathrm{EC}_{50}$ values, Alamar Blue was not always the most sensitive dye. This observation seemed $\log \mathrm{K}_{\mathrm{ow}}$ dependent: For chemicals with a low $\log \mathrm{K}_{\mathrm{ow}}<5$, Alamar Blue was with 1.7-fold lower $\mathrm{NtC}$ values generally most sensitive, while for chemicals characterized by a $\log \mathrm{K}_{\mathrm{ow}}>5$ as well as for Hel $\left(\log \mathrm{K}_{\mathrm{ow}}=4.33\right)$, CFDA-AM was most sensitive, resulting in 2.5-fold lower $\mathrm{NtC}$ values compared to Alamar Blue. As described for the $\mathrm{EC}_{50}$ values, this observation may hint toward different mechanisms of chemical action, such as stronger integration into the cell membrane of the more hydrophobic chemicals. Future studies could focus on the link between NtCs obtained with different cell viability indicators, mechanisms of action of chemicals as well as the potential of NtCs for extrapolation to sub-lethal impacts in vivo after prolonged chemical exposure. For the time being, NtCs are essen- tial as a prerequisite for cell line-based downstream applications such as biotransformation assessment (Stadnicka-Michalak et al., 2018a) or the transfer of chemical across the fish intestinal barrier (Schug et al., 2018).

\subsection{Comparison of in vitro and in vivo values}

The RTgutGC-based EC $_{50}$ values obtained in this study (Tab. $\mathrm{S}^{1}$ ) were first plotted against either the measured or the ECOSAR-predicted fish acute $\mathrm{LC}_{50}$ values (Tab. 1 and displayed in Fig. $\mathrm{S}^{1}$ ), calculating the regressions with the in vitro $\mathrm{EC}_{50}$ values on the $\mathrm{x}$-axis and in vivo $\mathrm{LC}_{50}$ values on the $\mathrm{y}$-axis because the final aim is to predict in vivo from in vitro data.

Strong linear in vitro-to-in vivo relationships were found independent of the type of cell viability measure and whether $\mathrm{EC}_{50}$ values were based on nominal or geometric mean of measured concentrations (Fig. S6 ${ }^{1}$ ). As previously shown (Natsch et al., 2018; Tanneberger et al., 2013), this observation suggests that, in principle, in vitro data based on nominal concentrations can be used to predict in vivo fish toxicity from the fish cell line data, especially if chemical quantification is unavailable. However, using measured concentrations will always add confidence. Having an additional time point for chemical analysis, as presented in this study, did not influence the $\mathrm{EC}_{50}$ derivations based on measured concentrations (data not shown). Thus, to keep the experimental load to a minimum, measurements at the beginning and at the end of the exposure time appear sufficient to determine actual 

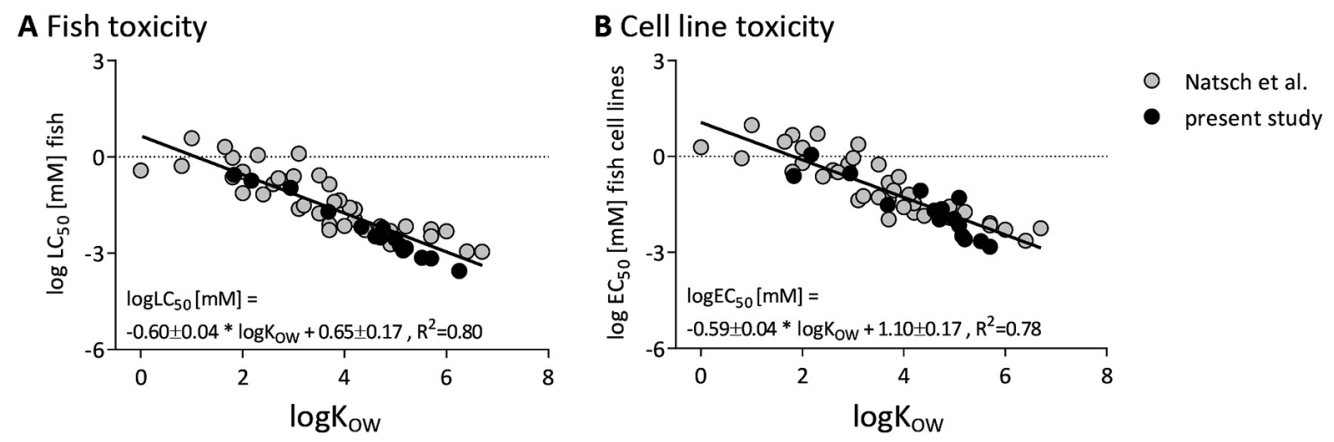

Fig. 3: Quantitative structure-activity relationship (QSAR) for fish and cell line toxicity based on cell metabolic activity The QSARs for acute toxicity were derived from plotting the measured log $\mathrm{K}_{\mathrm{ow}}$ against fish $\mathrm{LC}_{50}$ values using measured and predicted data (Panel A) and the cell line $\mathrm{EC}_{50}$ based on metabolic activity and measured concentration data (Tab. S5 ${ }^{1}$ ) (Panel B). Data from the present study (black circle, $n=16$ ) and from Natsch et al. (2018) (grey circles, $n=38$ ) were used. All toxicity data were used in molar concentrations, and cell line data were based on the endpoint metabolic activity. QSARs based on the two other endpoints, cell and lysosomal membrane integrity, can be found in Figure $\mathrm{S}^{1}{ }^{1}$. Solid lines and equation present a linear regression fitted against the mean of all data points.

exposure concentrations as suggested previously (Fischer et al., 2019; Natsch et al., 2018; Tanneberger et al., 2013).

The slopes of the correlations of cell-derived $\mathrm{EC}_{50}$ values with ECOSAR-predicted fish acute $\mathrm{LC}_{50}$ values were, with 1.1-1.5, consistently above one, while for the correlation with the measured fish acute $\mathrm{LC}_{50}$ values they were, with 0.69-0.97, consistently below one (regression lines resulting from dark symbols vs. light symbols in Fig. S6 ${ }^{1}$ ). At the same time, intercepts were closer to zero in the correlations with the measured fish acute toxicity data than with the predicted values. These observations indicate that the in vitro-to-in vivo correlation is stronger if the predictive model is based on measured in vivo $\mathrm{LC}_{50}$ data, a finding that has been pointed out previously (Natsch et al., 2018).

We next combined the in vivo and in vitro data for fragrances available from Natsch et al. (2018) with the present study (Fig. 2 for metabolic activity, Fig. $S 7^{1}$ for cell and lysosomal membrane integrity). Again, using measured chemical concentrations improved the correlation (Fig. 2A vs. 2B), as did merging the RTgill-W1 and RTgutGC data sets (Fig. 2C), resulting in the following relationship:

$\log \mathrm{LC}_{50}[\mathrm{mg} / \mathrm{L}]=1.03( \pm 0.05) * \log \mathrm{EC}_{50}-0.50( \pm 0.07)$

Eq. 1

This relationship can now be used for in vitro-to-in vivo extrapolation, specifically for the chemical class of fragrances using either the RTgutGC or the RTgill-W1 cell line to derive fish acute toxicity from in vitro $\mathrm{EC}_{50}$ values. As well, given the closeness of all observed relationships to the line of unity, along with considering the uncertainty observed in in vivo acute fish toxicity measurements (Fischer et al., 2019; Hrovat et al., 2009), it can be argued that the RTgill-W1 or RTgutGC cell line results can be used at face value, i.e., without a prediction model.

\subsection{Derivation of QSARs}

While the above given relationship allows the prediction of fish acute toxicity for fragrances from in vitro experiments, QSARs may allow extrapolation of acute toxicity outcomes from the chemicals' physicochemical properties. As most fragrances act mainly via baseline toxicity (Natsch et al., 2018), the $\log \mathrm{K}_{\mathrm{ow}}$ is an important factor for QSAR development. Accordingly, we derived QSARs for fragrances based on all available data: measured $\log \mathrm{K}_{\mathrm{ow}}$, in vivo fish acute $\mathrm{LC}_{50}$ data (measured and predicted combined), and the cell-based data from this study and the study by Natsch et al. (2018) (Fig. 3, Eq. 2 and 3 for metabolic activity, Fig. $\mathrm{S} 8^{1}$ for cell and lysosomal membrane integrity):

Fish toxicity: $\log \mathrm{LC}_{50}[\mathrm{mM}]=-0.60( \pm 0.04) * \log \mathrm{K}_{\mathrm{ow}}+0.65( \pm 0.17)$

Cell toxicity: $\log \mathrm{EC}_{50}[\mathrm{mM}]=-0.59( \pm 0.04) * \log \mathrm{K}_{\mathrm{ow}}+1.10( \pm 0.17)$

Both fish and cell line toxicity data showed a strong correlation with the measured $\log \mathrm{K}_{\mathrm{ow}}$, confirming the assumption that fragrances do not exhibit specific modes of toxicity, neither in fish nor in the cell lines. Interestingly, also the $\mathrm{NtCs}$ resulted in a comparable linear regression, albeit with a slightly inferior coefficient of determination $\left(\mathrm{R}^{2}=0.65\right.$ for $\mathrm{NtC}$ versus 0.78 for $\mathrm{EC}_{50}$; based on cell metabolic activity, Fig. $\mathrm{S}^{1}$ ). This result indicates 
that, in principle, QSARs could be used to derive $\mathrm{NtCs}$ for acute cell line toxicity as well.

\section{Conclusion}

This study supports the concept of using cell-based assays as predictive tools for fish acute toxicity, in line with already published studies (Tanneberger et al., 2013; Natsch et al., 2018; Fischer et al., 2019). Despite originating from different laboratories and different fish cell lines (Natsch et al., 2018; the present study), the two thus far available data sets for fragrances are in excellent agreement and, if combined, provide strong prediction models for fish acute toxicity without the need to use fish. Moreover, the use of cell-based concentration response curves to calculate $\mathrm{NtCs}$ provides a straight-forward means for concentration selection for downstream applications, such as cell-based biotransformation assessment or chemical transfer across cellular barriers. In future studies it would be interesting to test chemicals with different modes of action and compare the results between the two cell lines. Such information may lead to a better understanding of the capacity of the two cell lines to predict fish acute toxicity for certain chemical classes and modes of action, for example, due to the possession of different capacities to biotransform chemicals (Stadnicka-Michalak et al., 2018a).

\section{References}

Armitage, J. M., Erickson, R. J., Luckenbach, T. et al. (2016). Assessing the bioaccumulation potential of ionizable organic compounds: Current knowledge and research priorities. Environ Toxicol Chem 36, 882-897. doi:10.1002/etc.3680

Bols, N. C., Barlian, A., Chirino-Trejo, M. et al. (1994). Development of a cell line from primary cultures of rainbow trout, Oncorhynchus mykiss (Walbaum), gills. J Fish Dis 17, 601611. doi:10.1111/j.1365-2761.1994.tb00258.x

EC - European Commission (2006). Regulation (EC) No 1907/2006 of the European Parliament and oft he Council of 18 December 2006 concerning the Registration, Evaluation, Authorisation and Restriction of Chemicals (REACH), establishing a European Chemicals Agency, amending Directive 1999/45/EC and repealing Council Regulation (EEC) No 793/93 and Commission Regulation (EC) No 1488/94 as well as Council Directive 76/769/EEC and Commission Directives 91/155/EEC, 93/67/EEC, 93/105/EC and 2000/21/EC. OJ L396, 1-849. http://data.europa.eu/eli/reg/2006/1907/oj

Fischer, M., Belanger, S. E., Berckmans, P. et al. (2019). Repeatability and reproducibility of the RTgill-W1 cell line assay for predicting fish acute toxicity. Toxicol Sci 169, 353-364. doi:10.1093/toxsci/kfz057

Geppert, M., Sigg, L. and Schirmer, K. (2016). A novel two-compartment barrier model for investigating nanoparticle transport in fish intestinal epithelial cells. Environ Sci Nano 3, 388-395. doi:10.1039/C5EN00226E

Hrovat, M., Segner, H. and Jeram, S. (2009). Variability of in vivo fish acute toxicity data. Regul Toxicol Pharmacol 54, 294300. doi:doi:10.1016/j.yrtph.2009.05.013

ISO - International Organisation for Standardisation (2019). ISO21115:2019: Water quality - Determination of acute toxicity of water samples and chemicals to a fish gill cell line (RTgillW1). https://www.iso.org/standard/69933.html

Kawano, A., Haiduk, C., Schirmer, K. et al. (2011). Development of a rainbow trout intestinal epithelial cell line and its response to lipopolysaccharide. Aquacult Nutr 17, E241-E252. doi:10.1111/j.1365-2095.2010.00757.x

Langan, L. M., Harper, G. M., Owen, S. F. et al. (2017). Application of the rainbow trout derived intestinal cell line (RTgutGC) for ecotoxicological studies: Molecular and cellular responses following exposure to copper. Ecotoxicology 26, 1117-1133. doi:10.1007/s10646-017-1838-8

Lee, L. E. J., Clemons, J. H., Bechtel, D. G. et al. (1993). Development and characterization of a rainbow trout liver cell line expressing cytochrome P450-dependent monooxygenase activity. Cell Biol Toxicol 9, 279-294. doi:10.1007/BF00755606

Minghetti, M. and Schirmer, K. (2016). Effect of media composition on bioavailability and toxicity of silver and silver nanoparticles in fish intestinal cells (RTgutGC). Nanotoxicology 10, 1526-1534. doi:10.1080/17435390.2016.1241908

Minghetti, M., Drieschner, C., Bramaz, N. et al. (2017). A fish intestinal epithelial barrier model established from the rainbow trout (Oncorhynchus mykiss) cell line, RTgutGC. Cell Biol Toxicol 33, 539-555. doi:10.1007/s10565-017-9385-x

Natsch, A., Laue, H., Haupt, T. et al. (2018). Accurate prediction of acute fish toxicity of fragrance chemicals with the RTgill-W1 cellassay. Environ Toxicol Chem 37,931-941.doi:10. 1002/etc.4027

OECD (2014). Guidance Document on the Validation of (Quantitative) Structure-Activity Relationship [(Q)SAR] Models. OECD Series on Testing and Assessment No. 69. OECD Publishing, Paris. doi:10.1787/9789264085442-en

OECD (2019). Test No. 203: Fish, Acute Toxicity Test. OECD Guidelines for the Testing of Chemicals, Section 2. OECD Publishing, Paris. doi:10.1787/9789264069961-en

Raue, A., Kreutz, C., Maiwald, T. et al. (2009). Structural and practical identifiability analysis of partially observed dynamical models by exploiting the profile likelihood. Bioinformatics 25, 1923-1929. doi:10.1093/bioinformatics/btp358

Schirmer, K., Chan, A. G. J., Greenberg, B. M. et al. (1997). Methodology for demonstrating and measuring the photocytotoxicity of fluoranthene to fish cells in culture. Toxicol In Vitro 11, 107-119. doi:10.1016/S0887-2333(97)00002-7

Schirmer, K., Chan, A. G. J. and Bols, N. C. (2000). Transitory metabolic disruption and cytotoxicity elicited by benzo-apyrene in two cell lines from rainbow trout liver. J Biochem Mol Toxicol 14, 262-276. doi:10.1002/1099-0461(2000)14:5<262:: AID-JBT5>3.0.CO;2-2

Schirmer, K. (2006). Proposal to improve vertebrate cell cultures to establish them as substitutes for the regulatory testing of chemicals and effluents using fish. Toxicology 224, 163-183. doi:10.1016/j.tox.2006.04.042 
Schirmer, K., Tanneberger, K., Kramer, N. I. et al. (2008). Developing a list of reference chemicals for testing alternatives to whole fish toxicity tests. Aquat Toxicol 90, 128-137. doi:10.1016/j.aquatox.2008.08.005

Schreiber, R., Altenburger, R., Paschke, A. et al. (2008). How to deal with lipophilic and volatile organic substances in microtiter plate assays. Environ Toxicol Chem 27, 1676-1682. doi:10.1897/07-504.1

Schug, H., Begnaud, F., Debonneville, C. et al. (2018). TransFEr: A new device to measure the transfer of volatile and hydrophobic organic chemicals across an in vitro intestinal fish cell barrier. Analytical Methods 10, 4394-4403. doi:10.1039/ C8AY01253A

Schug, H., Yue, Y., Krese, R. et al. (2019). Time- and concentration-dependent expression of immune and barrier genes in the RTgutGC fish intestinal model following immune stimulation. Fish Shellfish Immunol 88, 308-317. doi:10.1016/j. fsi.2019.02.036

Stadnicka-Michalak, J., Weiss, F. T., Fischer, M. et al. (2018a). Biotransformation of benzo[ a]pyrene by three rainbow trout (Onchorhynchus mykiss) cell lines and extrapolation to derive a fish bioconcentration factor. Environ Sci Technol 52, 30913100. doi:10.1021/acs.est.7b04548

Stadnicka-Michalak, J., Knobel, M., Zupanic, A. et al. (2018b). A validated algorithm for selecting non-toxic chemical concentrations. ALTEX 35, 37-50. doi:10.14573/altex.1701231

Tanneberger, K., Rico-Rico, A., Kramer, N. I. et al. (2010). Ef- fects of solvents and dosing procedure on chemical toxicity in cell-based in vitro assays. Environ Sci Technol 44, 4775-4781. doi:10.1021/es100045y

Tanneberger, K., Knobel, M., Busser, F. J. M. et al. (2013). Predicting fish acute toxicity using a fish gill cell line-based toxicity assay. Environ Sci Technol 47, 1110-1119. doi:10.1021/ Es303505z

Wang, J., Lei, P., Gamil, A. A. A. et al. (2019). Rainbow trout (Oncorhynchus mykiss) intestinal epithelial cells as a model for studying gut immune function and effects of functional feed ingredients. Front Immunol 10, doi:10.3389/fimmu. 2019.00152

Yue, Y., Behra, R., Sigg, L. et al. (2015). Toxicity of silver nanoparticles to a fish gill cell line: Role of medium composition. Nanotoxicology 9, 54-63. doi:10.3109/17435390.2014.889236

\section{Conflict of interest}

There are no conflicts of interest to declare.

\section{Acknowledgments}

This research was financially supported by the Swiss Commission for Technology and Innovation (CTI, contract number 17100.1 PFIW-IW) and Firmenich SA. We thank Helmut Segner (University Bern) and Christian Kropf (University Bern) for the excellent collaboration, advice and discussions. 